Part of Journal of Research of the National Bureau of Standards, Volume 19, December 1937

\title{
NEW TEST FOR DIMENSIONAL CHANGES IN OFFSET PAPERS
}

\author{
By Charles G. Weber and Martin N. V. Geib
}

\begin{abstract}
Change of dimension of paper is a serious factor in many of its uses, particularly in multicolor offset printing where changes of dimensions cause the greatest difficulty-misregister of prints. The changes are caused by variations in the relative humidity of the surrounding air. To predict the relative constancy of dimensions of papers in use, a method was devised for determining the expansivity of paper with variations in relative humidity. Specimens of paper approximately 24 inches in length are mounted under constant tension in a cabinet in which humidity is controlled by salt solutions. Changes of length of the paper are measured by means of an optical lever, with a sensitivity of 0.00025 inch and the humidity and temperature inside the cabinet are determined with a wet- and dry-bulb hygrometer. The data thus obtained checked closely with those obtained by measuring specimens on a flat surface with a micrometer rule and were much more conveniently obtained and more reproducible.
\end{abstract}

\section{CONTENTS}

I. Introduction

II. Description of the apparatus

III. Effects of some conditions of testing

1. Stress on specimen

2. Effects of expansion and contraction of the cabinet....... 669

3. Precision of measurements . .

IV. Measurements on typical papers ... 671

V. Suggested method of test for expansivity of offset papers _._.

1. Apparatus

2. Specimen

3. Procedure

\section{INTRODUCTION}

The changes of dimensions of paper with changes of moisture content are serious in offset papers used for multicolor printing and for other purposes where nearly constant dimensions are desired. The expansivity of such papers has been determined at the National Bureau of Standards by measuring with a micrometer rule specimens 24 or more inches in length, under different atmospheric conditions. ${ }^{1}$ While satisfactory results can be obtained in this manner, the method requires the operation of a testing chamber at two or more widely different humidities, and is practicable only for research purposes. Numerous methods of determining the expansivity of paper have been proposed but not considered satisfactory because tests were generally

1 BS J. Research 9, 431 (Sept. 1932) RP480. 
made on small specimens and with devices in which the exact conditions surrounding the specimens were not conveniently controlled and measured.

The new method permits the testing of specimens of length sufficient to give a reliable reading, and wide enough to permit a load sufficient to minimize the effects of friction without excessive stretch. The apparatus is self-contained to the extent that it can be used under ordinary room conditions, hence it is adapted to use in the laboratory, print shop, or mill.

This study is one of a series made with the cooperation and financial support of the Lithographic Technical Foundation, paper manufacturers, printing-equipment manufacturers, and air-conditioning engineers. The studies are planned with the counsel of an advisory committee composed of technical representatives of the cooperating firms under the chairmanship of Prof. R. F. Reed, Director of Lithographic Research, University of Cincinnati.

\section{DESCRIPTION OF THE APPARATUS}

The apparatus consists essentially of a wooden cabinet approximately 40 in. high, 16 in. wide, and 12 in. deep, inside dimensions. Relative humidity inside the cabinet is controlled by circulating the air with a motor-driven fan over a suitable salt solution within a tray in the base.

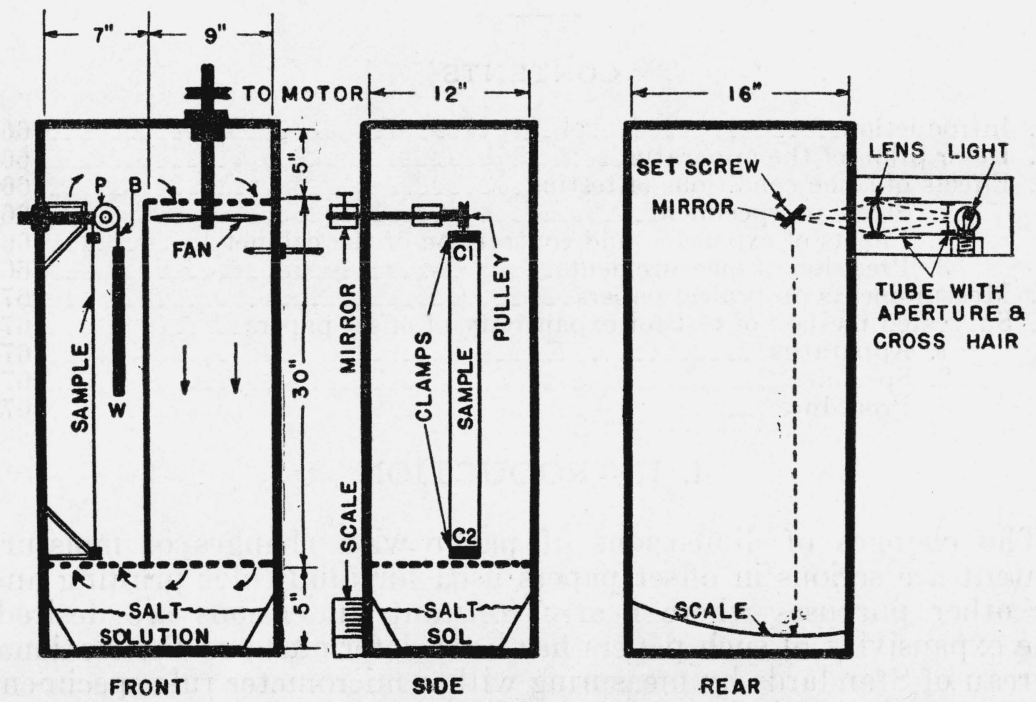

FIGURE 1.-Apparatus for determining the relative expansivity of papers.

The construction of the apparatus is shown in figure 1, which also shows the division of the cabinet to assure positive circulation over the salt solution and around the specimen under test.

The specimen is placed in the clamps shown. The lower clamp, $C 2$, is fixed, and the upper one, $C 1$, is suspended from a light, flexible cable, $B$, which leads over the pulley, $P$. Tension is applied to the 
specimen by a dead-weight load on the other end of the cable at $W$, the tension being equal to the difference between the total load and the load required to move the upper jaw. The pulley shaft extends through the back of the cabinet and a mirror is mounted on the end outside the cabinet. Movement of the mirror, through rotation of the shaft, changes the position of a spot of light reflected by the mirror to a graduated scale near the base of the cabinet. The beam originates from the tube shown. Light from the source, a 40-watt bulb, admitted through a $1 / 8$-in. circular aperture with a horizontal cross hair through its center, is focused onto the mirror by a 2 -in. double convex lens near the other end of the tube. The mirror is mounted at an angle to reflect the beam of light onto the scale where the image of the cross hair makes a very satisfactory reading line. The tube is made in two sections, telescoped one within the other, to permit moving the section containing the lens so as to adjust the focus on the mirror to obtain a sharp image on the scale. The sections are 4 in. in length, telescoped to form a tube approximately $6 \mathrm{in}$. long. This tube is so placed that the lens is approximately $7 \frac{1}{2} \mathrm{in}$. from the mirror. The cross hair is a copper wire 0.005 in. in diameter (no. $36 \mathrm{AWG}$ ), and the lens is from an ordinary hand reading glass, having a focal length of 4.9 in. (8.00 diopters).

Expansion or contraction of the specimen turns the shaft through travel of the cable over the pulley. Using the ratio of the radius of the pulley to the distance of the mirror from the scale, which is the radius of curvature of the scale, the change in length of the specimen can be calculated from the travel of the light beam on the scale. The scale on the apparatus was calibrated for direct reading by raising and lowering clamp $C_{2} 2$, measuring its movement with a micrometer caliper, and correlating this movement with the scale readings. The readings were found to be $2 \mathrm{~cm}$ per 0.01 -in. movement of the clamp, hence the smallest scale division, $0.1 \mathrm{~cm}$, corresponds to 0.0005 -in. expansion. It was read to the nearest half of a scale division in the tests reported.

The cabinet is constructed of wood, $1 \mathrm{in}$. thick, covered on the inside with a heavy coating of wax and painted inside and outside with asphalt paint to minimize infiltration of air and moisture. The entire front is a hinged door which closes against a small rubber tube as a seal. The door is divided at the top of the bottom compartment so that the salt-solution trays can be interchanged without opening the remainder of the cabinet. The atmospheric conditions inside the cabinet are ascertained from wet and dry bulb readings taken in the air stream 3 in. below the fan by inserting the thermometers through holes provided in the door. The circulating fan is 8 in. in diameter and operates at 1,450 rpm. The air speed, as determined with a tube type of velocimeter, is 500 feet per minute around the specimen and 800 feet around the thermometer bulbs. This rapid circulation quickly brings the vapor pressure of the air to a steady state, conditions the test specimen rapidly, and ensures reliable wet-bulb readings. ${ }^{2}$

A wide range of humidities is obtainable by the use of different salt solutions or other materials suitable for controlling vapor pressure. Data for a selected list of solutions suitable for most requirements are given in an article by Carson. ${ }^{3}$

2 F. T. Carson. Paper Trade J. 94, no. 2 (January 14, 1932).

3 F. T. Carson, Paper Trade J. 93, no. 18 (October 29, 1931). 


\section{EFFECTS OF SOME CONDITIONS OF TESTING}

\section{STRESS ON SPECIMEN}

In order to obtain data on the importance of stress, the same paper was tested under dead-weight tensions ranging from 50 to $1,000 \mathrm{~g}$ for the specimens 2 in. in width. The results are shown graphically in figure 2. The data were obtained for a range of relative humidities of

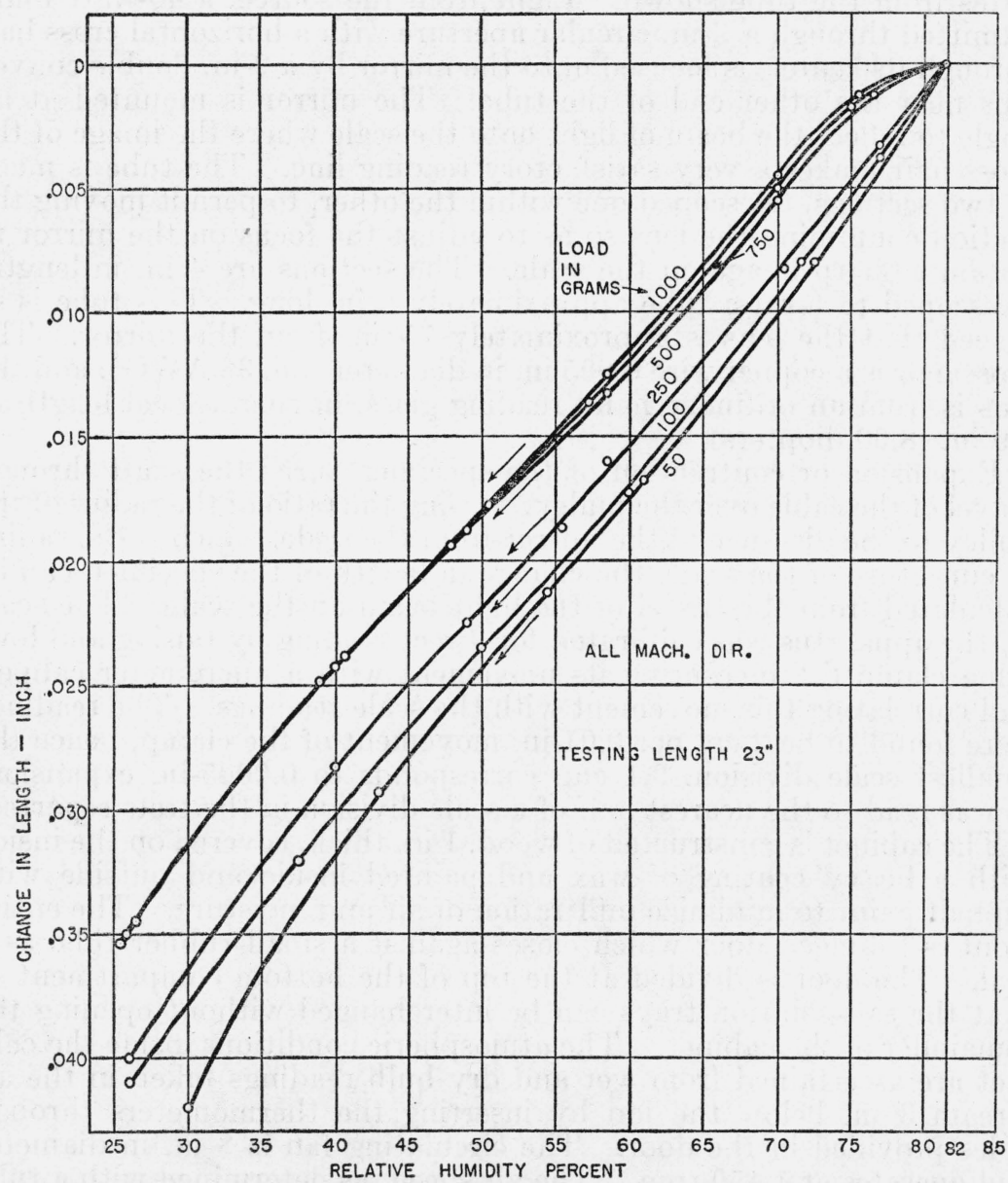

FIGURE 2.-Effect of tension on the hygrometric expansivity of offset paper; desorption curves for the same paper with different tensions.

82 to 26 percent. In order to avoid variations due to hysteresis effects, the same procedure was followed for each determination. The specimen was mounted and conditioned first at 50-percent relative humidity, then to the starting point at 82 percent. From this point, the specimen was conditioned at the other humidities indicated, in order of decreasing values. Scale readings for length of specimen and wet- and dry-bulb readings for relative humidity were taken for each condition after the specimen had reached constant length. 
Although increased tension resulted in stretch of the specimen as indicated by separation of the curves, for the range of tensions used, nearly all the stretch occurred at humidities above 70 percent. Varying the tension from 25 to $500 \mathrm{~g}$ per inch of width did not change appreciably the slope of the curve in the region below 70-percent humidity. Hence, if the expansivity is taken from this part of the curve, precise control of tension is not important. For further experiments reported herein, a tension of $50 \mathrm{~g}$ per inch of width was used.

\section{EFFECTS OF EXPANSION AND CONTRACTION OF THE CABINET}

The magnitude of the possible errors introduced by thermal and hygrometric expansivity of the cabinet itself was investigated by using as the test specimen a steel tape having a known coefficient of expansion. The results of expansivity tests of the steel tape are shown in table 1.

The wood in the cabinet appears to be quite effectively sealed against moisture as shown by the slight errors caused by large humidity changes. However, the thermal effects are apparent and large variations in temperature during a test should be avoided.

TABLE 1.-Results of expansivity tests of steel tape showing errors due to thermal and hygrometric expansivity of the cabinet

\begin{tabular}{|c|c|c|c|c|}
\hline $\begin{array}{l}\text { Relative- } \\
\text { humidity } \\
\text { change }\end{array}$ & $\begin{array}{l}\text { Tempera- } \\
\text { ture change }\end{array}$ & $\begin{array}{c}\text { Scale-reading } \\
\text { change }\end{array}$ & $\begin{array}{l}\text { Thermal } \\
\text { change of } \\
\text { length of } \\
\text { tape } 1 \text { (com- } \\
\text { puted) }\end{array}$ & $\begin{array}{l}\text { Apparent } \\
\text { error of read- } \\
\text { ing caused } \\
\text { by change } \\
\text { of cabinet }\end{array}$ \\
\hline $\begin{array}{c}\text { Percent } \\
+27 \\
-50 \\
0 \\
+1 \\
-3 \\
+1\end{array}$ & $\begin{array}{l}\circ \mathrm{C} \\
+3.0 \\
+0.6 \\
+3.0 \\
+2.2 \\
-2.4 \\
+2.4\end{array}$ & \begin{tabular}{c} 
Inch \\
+0.0005 \\
0 \\
+.00075 \\
+.00025 \\
\hdashline .00025 \\
+.00075
\end{tabular} & $\begin{array}{c}\text { Inch } \\
+0.0008 \\
+.00016 \\
+.00080 \\
+.00058 \\
+.00064 \\
+.00064\end{array}$ & $\begin{array}{c}\text { Inch } \\
0.00030 \\
.00016 \\
.00005 \\
.00033 \\
.00039 \\
.00011\end{array}$ \\
\hline
\end{tabular}

1 Coefficient of expansion of tape 0.0000116 per degree centigrade.

\section{PRECISION OF MEASUREMENTS}

Comparative tests were made to learn how well the data obtained with the method compared with those obtained by measuring the papers on a flat surface with the micrometer rule. Satisfactory agreement was obtained, as illustrated by the data given in table 2 .

TABLE 2.-Comparison of expansion data obtained by two methods

\begin{tabular}{|c|c|c|c|c|}
\hline \multicolumn{3}{|c|}{ Measurements made with micrometer rule } & \multicolumn{2}{|c|}{$\begin{array}{l}\text { Direct readings with } \\
\text { expansivity } \\
\text { (100-g tension) }\end{array}$} \\
\hline Paper & $\begin{array}{c}\text { Expansion } \\
\text { between } \\
50-\text { and } 65- \\
\text { percent } \mathrm{rh}\end{array}$ & $\begin{array}{l}\text { Average } \\
\text { deviation } \\
\text { of five } \\
\text { readings }\end{array}$ & $\begin{array}{c}\text { Expansion } \\
\text { between } \\
50 \text { - and } 65- \\
\text { percent rh }\end{array}$ & $\begin{array}{c}\text { Average } \\
\text { deviation } \\
\text { of five } \\
\text { readings }\end{array}$ \\
\hline $\begin{array}{l}A \\
B \\
C\end{array}$ & $\begin{array}{r}\text { Percent } \\
0.062 \\
.067 \\
.049\end{array}$ & $\begin{array}{l}\text { Inch } \\
0.0022 \\
.0007 \\
.0009\end{array}$ & $\begin{array}{r}\text { Percent } \\
0.065 \\
.070 \\
.054\end{array}$ & $\begin{array}{r}\text { Inch } \\
0.0002 \\
.0003 \\
.0003\end{array}$ \\
\hline
\end{tabular}


The slightly higher values obtained in the cabinet can be attributed to the tension on the specimens. When no tension is applied, expan-

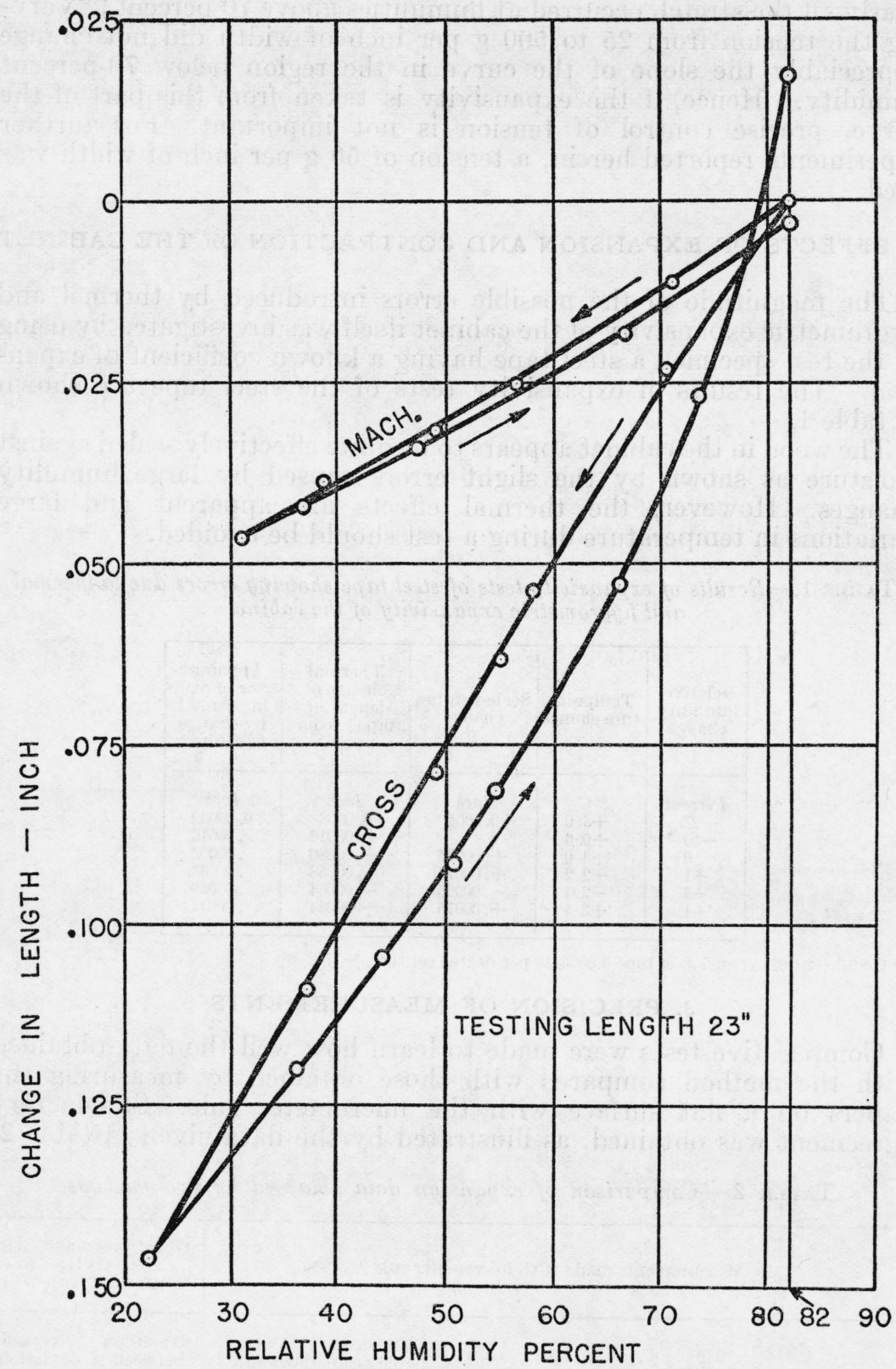

FIGURE 3.-Curves showing changes of dimensions of offset paper for a complete cycle of humidity changes, from 82 percent to 23 percent by desorption and back to the starting point by adsorption.

sion and contraction of paper are accompanied by distortion in the form of waving and curling, and this distortion probably is never 
completely "ironed out" when measuring on a flat surface. Better reproducibility in individual readings was obtained with the expansivity tester as shown by the average deviation of readings.

The sensitivity of the method was found satisfactory. The scale divisions are comparatively large, and are easily read to the nearest half, which is 0.00025 in. The expansion measured is of the order of 0.065 percent which is 0.015 in. for a 23 -in. sample. Hence when the readings are made to 0.00025 in. the precision is approximately 1 part in 60 .

One potential source of error in the expansivity determination is in the measurement of relative humidity. This is determined only to the nearest 0.5 percent; hence, if measurements are made at only two points, differing by 15 percent in relative humidity, an uncertainty of 1 part in 30 is thereby introduced. If, however, measurements are made at several points, and a smooth curve is drawn and used as a basis for finding the hygrometric expansivity, the probable error from this source is greatly reduced.

\section{MEASUREMENTS ON TYPICAL PAPERS}

Measurements were made on a series of lithographic papers, and curves plotted from the data on a typical paper are shown in figure 3. These curves show changes in length for cross and machine directions for the complete cycle of humidity changes from the starting point at 82 percent. They have the same general form as typical moisture regain curves for similar humidity cycles. ${ }^{4}$

Curves for the data on four lithographic papers of different fiber composition are shown in figure 4. The hygrometric expansivity of these papers can be computed from their curve by dividing the change in length for a given humidity range by the testing length, 23 in. The curves are approximately straight in the region of $40-$ to 65 -percent relative humidity, and it appears satisfactory to base the expansivity per unit of relative humidity change on that region of the curve. For example, in figure 4, curve $A$ shows a linear change of 0.0134 in., or $0.0134 / 23=0.058$ percent, and $C 0.0094$ in. or $0.0094 / 23$ $=0.041$ percent between 65 -percent and 50-percent relative humidity.

For the various conditions of relative humidity at which the data given were obtained, the solutions and solid substances listed in table 3 were used.

TABLE 3.--Solutions used to control relative humidity

\begin{tabular}{|c|c|c|}
\hline Solution or solid substance & $\begin{array}{l}\text { Relative hu- } \\
\text { midity cor- } \\
\text { responding } \\
\text { to vapor } \\
\text { pressure of } \\
\text { solution }\end{array}$ & $\begin{array}{l}\text { Relative hu- } \\
\text { midity ob- } \\
\text { tained in the } \\
\text { cabinet }\end{array}$ \\
\hline $\begin{array}{l}\text { Potassium sulphate (saturated sol.) } \\
\text { Barium chloride (saturated sol.) } \\
\text { Sodium chloride (saturated sol.) } \\
\text { Sodium bromide (saturated sol.) }\end{array}$ & $\begin{array}{c}\text { Percent } \\
95 \\
88 \\
75.8 \\
58\end{array}$ & $\begin{array}{l}\text { Percent } \\
82 \text { to } 83 \\
76 \text { to } 78 \\
66 \text { to } 71 \\
56 \text { to } 59\end{array}$ \\
\hline $\begin{array}{l}\text { Sodium dichromate (saturated sol.) } \\
\text { Potassium carbonate (saturated sol.) } \\
\text { Magnesium chloride (crystals) } \\
\text { Calcium chloride (solid) }\end{array}$ & $\begin{array}{r}52 \\
43 \\
33 \\
-\end{array}$ & $\begin{array}{l}50 \text { to } 57 \\
44 \text { to } 49 \\
36 \text { to } 38 \\
24 \text { to } 27\end{array}$ \\
\hline
\end{tabular}

4 BS J. Research 12, 53 (Jan. 1934) R P633. 
It will be noted that the relative humidities obtained were not, in most instances, the conditions ascribed to the solution or chemical. This apparent inconsistency between the observed and the expected humidities is doubtless explained largely by temperature differences between that of the air in the cabinet and the temperature of the conditioning substance. Evaporation to obtain a high humidity cools the solution and condensation to dehumidify warms the solution.

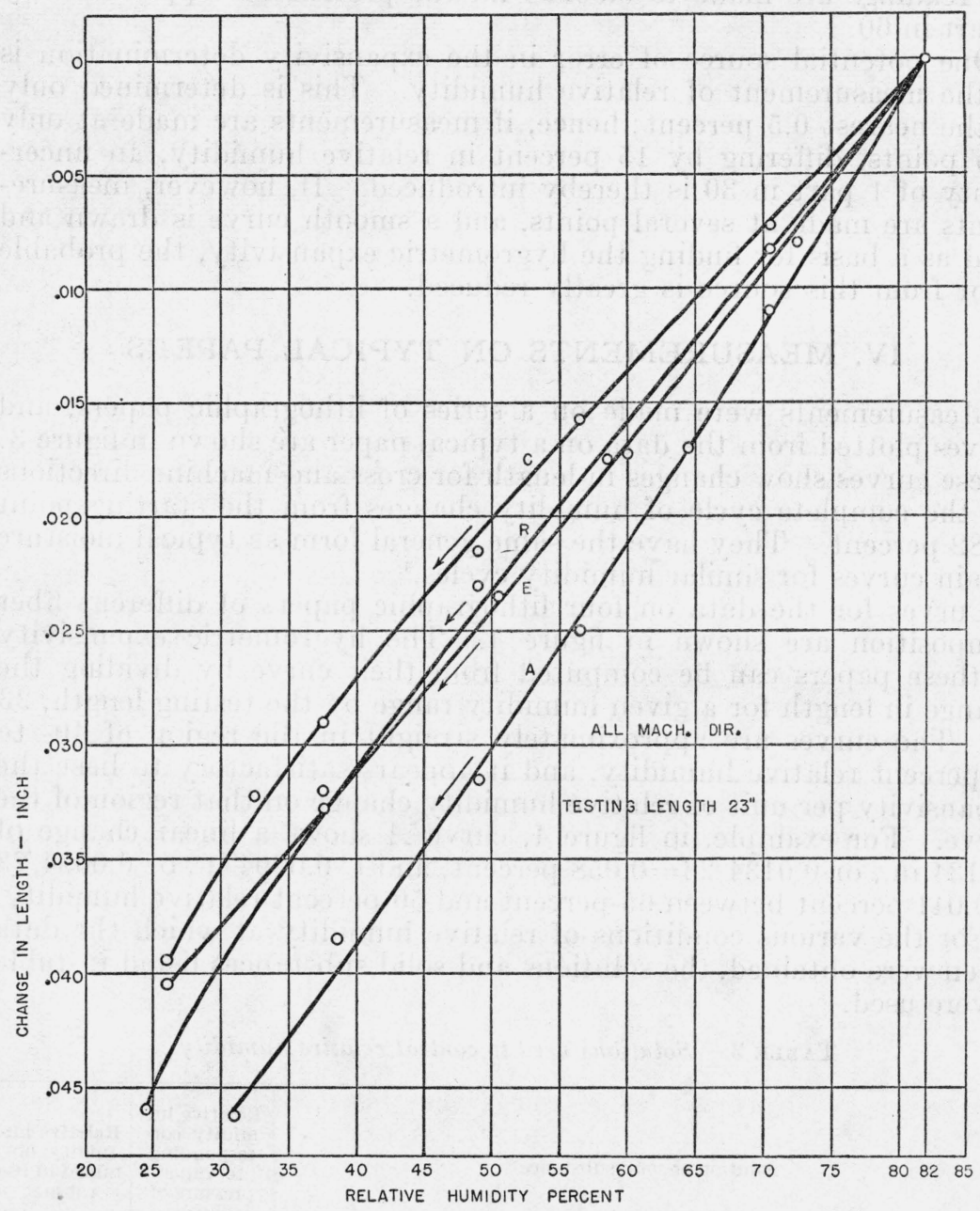

FIGURE 4.-Expansivity curves for four typical offset papers; desorption curves.

Differences as great as $3^{\circ} \mathrm{C}$ were noted in the operation. No attempt was made to exactly obtain any predetermined humidity, but simply to obtain a suitable range of humidities for plotting a curve and to exactly measure each condition.

Although the data shown are for lithographic papers, a wide variety of types have been tested with equally good results, and the method is considered suitable for papers in general. 


\section{SUGGESTED METHOD OF TEST FOR EXPANSIVITY OF OFFSET PAPERS}

\section{APPARATUS}

The apparatus should consist of a cabinet of the design and approximate size shown in figure 1. The pulley shaft should be free to turn in ball or other low-friction bearings, and the fan should provide an air flow around the specimen of not less than 500 feet per minute. The mirror should be so clamped to the shaft as to permit simple adjustment to obtain a zero setting when the specimen is mounted. The cable connecting the upper clamp and the weight should be very flexible to prevent slippage. If constructed of wood, the cabinet should be coated on the inside and outside with a moisture-resistant coating, metal-lined, or otherwise treated to minimize swelling. ${ }^{5}$ If constructed of metal, it should be insulated.

\section{SPECIMEN}

The specimen should be cut 2 in. wide and approximately 25 in. long, with the long dimension parallel to the major direction for which data are desired.

\section{PROCEDURE}

The specimen is mounted in the cabinet under a tension of $50 \mathrm{~g}$ per inch of width, and conditioned first at a relative humidity of 50 percent or lower, then at 80 percent or above. When the length becomes constant at the high humidity, the zero setting is made by adjusting the position of the mirror. Data for an expansion curve as illustrated in figure 4 are then obtained by conditioning at two or more lower humidities in order of decreasing values, ranging down to 50 percent or below. Humidity determinations and scale readings are made for each condition and the changes of length are plotted against humidity as shown in figure 4. The expansivity value is taken from this curve. It is obtained by dividing the change in length between two convenient points on the regular part of the curve by the testing length of the specimen. Relative humidities of 50- and 65-percent are usually convenient points to use when expressing the hygrometric expansivity as a percentage change of length per 15 percent relative humidity change. Data on one specimen are sufficient for an ordinary test; however, in instances where smooth curves are not obtained, check tests should be made.

The thermometers used for determining wet- and dry-bulb temperatures should conform to the following specifications: range, 0 to $50^{\circ}$ $\mathrm{C}\left(32\right.$ to $\left.122^{\circ} \mathrm{F}\right)$; graduation, $0.2^{\circ} \mathrm{C}\left(0.5^{\circ} \mathrm{F}\right)$. They should be matched to within $0.1^{\circ} \mathrm{C}\left(1 / 4^{\circ} \mathrm{F}\right)$ throughout the range used. Temperatures should be taken with the bulbs in the air stream where the velocity of air is not less than 10 feet per second.

The temperature of the air surrounding the cabinet should not vary more than $\pm 5^{\circ} \mathrm{F}$ while a test is in progress.

Washington, October 1, 1937.

${ }^{5}$ A. J. Stamm. Arch. Record (Feb. 1937). 